Res., Soc. Dev. 2019; 8(2):e782561

ISSN 2525-3409 | DOI: http://dx.doi.org/10.33448/rsd-v8i2.561

\title{
A percepção dos alunos sobre a infraestrutura do Ifpb - Campus Guarabira
}

The perception of students on infrastructure Ifpb - Campus Guarabira

La percepción de los alumnos sobre la infraestructura del Ifpb - Campus Guarabira

Valdir Cruz da Silva

Instituto Federal da Paraíba - IFPB - Campus Guarabira, Brasil

E-mail: valdircruzdasilva@gmail.com

Anna Cecília Chaves Gomes

ORCID: https://orcid.org/0000-0002-2254-7950

Instituto Federal da Paraíba - IFPB - Campus Guarabira, Brasil

E-mail: anna.gomes@ifpb.edu.br

Recebido: 07/08/2018 - Aceito: 20/08/2018

\section{Resumo}

A infraestrutura é parte de significativa importância no processo de ensino-aprendizagem de uma instituição educacional em virtude de oferecer o suporte necessário para o pleno desempenho das funções acadêmicas, administrativas, como também, proporciona satisfação para o aluno e a sociedade em geral. Nesse contexto o presente artigo busca analisar a percepção dos alunos do Instituto Federal da Paraíba - IFPB Campus Guarabira, sobre a infraestrutura que o Campus oferece. Para este fim, foi elaborado um questionário com 39 perguntas com base nos autores Pieri e Santos (2014), contendo aspectos de existência ou não dos itens de infraestrutura. O universo da pesquisa é composto por 528 alunos regularmente matriculados. Foi realizada uma amostragem aleatória simples com nível de confiança de 95\% e 5\% de erro, totalizando uma amostra com 168 participantes, onde foi possível observar que os itens pesquisados estão dentro de uma qualidade esperada para os alunos, contudo foi observado também que é urgente uma melhora em alguns itens visando o pleno desenvolvimento da vida estudantil dos alunos.

Palavras-chave: Infraestrutura; Qualidade; Percepção.

\begin{abstract}
Infrastructure is part of significant importance in the teaching-learning process of an educational institution by virtue of providing the necessary support for the full performance of academic and administrative functions as well as providing satisfaction for the student and
\end{abstract}


society in general. In this context the present article seeks to analyze the perception of the students of the Federal Institute of Paraíba - IFPB Campus Guarabira, about the infrastructure that the Campus offers. For this purpose, a questionnaire with 39 questions was elaborated based on the authors Pieri and Santos, (2014), containing aspects of existence or not of the infrastructure items. The research universe is composed of 528 students who were regularly enrolled. A simple random sampling with $95 \%$ confidence level and 5\% error was performed, totaling a sample with 168 participants, where it was possible to observe that the items surveyed are within one expected quality for students, however, it was also observed that there is an urgent need to improve some of the items aimed at the full development of student life.

Keywords: Infrastructure; Quality; Perception.

\section{Resumen}

La infraestructura es parte de significativa importancia en el proceso de enseñanzaaprendizaje de una institución educativa en virtud de ofrecer el soporte necesario para el pleno desempeño de las funciones académicas, administrativas, como también, proporciona satisfacción para el alumno y la sociedad en general. En este contexto el presente artículo busca analizar la percepción de los alumnos del Instituto Federal de Paraíba - IFPB Campus Guarabira, sobre la infraestructura que el Campus ofrece. Para este fin, se elaboró un cuestionario con 39 preguntas con base en los autores Pieri y Santos (2014), conteniendo aspectos de existencia o no de los ítems de infraestructura. El universo de la investigación está compuesto por 528 alumnos regularmente matriculados. Se realizó un muestreo aleatorio simple con un nivel de confianza del $95 \%$ y un 5\% de error, totalizando una muestra con 168 participantes, donde fue posible observar que los ítems encuestados están dentro de una calidad esperada para los alumnos, sin embargo se observó también que es urgente una mejora en algunos ítems para el pleno desarrollo de la vida estudiantil de los alumnos.

Palabras clave: Infraestructura; la calidad; Percepción.

\section{Resumen}

La infraestructura es parte de significativa importancia en el proceso de enseñanzaaprendizaje de una institución educativa en virtud de ofrecer el soporte necesario para el pleno desempeño de las funciones académicas, administrativas, como también, proporciona satisfacción para el alumno y la sociedad en general. En este contexto el presente artículo busca analizar la percepción de los alumnos del Instituto Federal de Paraíba - IFPB Campus 
Guarabira, sobre la infraestructura que el Campus ofrece. Para este fin, se elaboró un cuestionario con 39 preguntas con base en los autores Pieri y Santos (2014), conteniendo aspectos de existencia o no de los ítems de infraestructura. El universo de la investigación está compuesto por 528 alumnos regularmente matriculados. Se realizó un muestreo aleatorio simple con un nivel de confianza del $95 \%$ y un 5\% de error, totalizando una muestra con 168 participantes, donde fue posible observar que los ítems encuestados están dentro de una calidad esperada para los alumnos, sin embargo se observó también que es urgente una mejora en algunos ítems para el pleno desarrollo de la vida estudiantil de los alumnos.

Palabras clave: Infraestructura; la calidad; Percepción.

\section{Introdução}

Em virtude da demanda crescente da população brasileira por uma educação de qualidade e do desenvolvimento do país nos últimos anos a Rede Federal de Educação Profissional deu um salto quantitativo significativo através de um avanço na implantação de novos centros educacionais no Brasil. A quantidade de unidades da Rede saltou de $140 \mathrm{em}$ 2002, para 562 unidades em 2014, um aumento de 400\% em pouco mais de 10 anos (MEC, 2017). E somente a Paraíba teve a abertura de 17 novos campi e 04 núcleos avançado do Instituto Federal (IFPB, 2017).

Conforme Pereira (2008), o processo de expansão dos centros educacionais, a partir de 2002, se fortaleceu com o intuito de abranger cada vez mais cidades e disseminando-se para as cidades do interior que são pólos das regiões. Sendo assim, não apenas tem-se instituições de ensino recém construídas, como também melhorias naquelas que já existiam.

Tal evidencia é ratificada segundo o Relatório da Comissão Constituída pela Portaria $n^{\circ} 126 / 2012$, que elenca uma série de dados no tocante a expansão do Sistema Federal de Educação Superior no período de 2003 a 2012, como: a construção de 368 laboratórios, 292 salas de aula, 43 bibliotecas, 61 restaurantes, 33 moradias, 182 espaços administrativos, 260 áreas multifuncionais, 67 apoios a comunidade, 43 áreas esportivas, 27 auditórios e 212 infraestrutura, totalizando 1.588 obras concluídas. (MEC, 2012).

A infraestrutura é parte integrante de fundamental importância para o pleno desenvolvimento do processo de ensino-aprendizagem, por dar o suporte essencial para o bom andamento dos métodos e técnicas acadêmicas que nortearão a vida estudantil do aluno.

De acordo com Soares Neto (2013), o processo de ensino aprendizagem depende da interação de vários fatores e que deve ser realizado da forma certa, requerendo desde um quadro de professores e técnicos administrativo qualificados, como também uma infraestrutura que abranjam desde materiais didáticos, equipamentos e estruturas físicas capazes de suprir todo o processo de ensino aprendizagem. 
Contudo, nem sempre o Estado consegue suprir a demanda da população por uma educação de qualidade. Melhorias na educação implicam não apenas em altas somas de capital, mas também em uma adequada aplicação destes. Mesmo quando os recursos são destinados, muitas vezes os gastos ocorrem de forma equivocada e distorcida da realidade, de forma que Santos (2016), afirma que os termos eficácia, eficiência e efetividade são cada vez más trabalhados, em busca de melhorias na aplicação do capital.

Sendo assim, o crescimento quantitativo não é suficiente para uma melhoria na qualidade do ensino. Este precisa ser acompanhado do qualitativo. Portanto, faz-se necessário uma análise de como está se dando a aplicação do capital nas instituições, sobretudo aquelas recém implantadas, dado que podem estar iniciando suas atividades sem a infraestrutura mínima necessária para garantir sua continuidade, exemplificando, o Campus Guarabira é um dos muitos campi implantados no processo de expansão e que, apesar de atuar a 6 anos, apenas recentemente iniciou suas atividades em sua sede definitiva.

Desta forma, a pesquisa apresenta ainda relevância empírica ao apontar uma diretriz que possa servir como parâmetro para uma melhoria considerável, tanto na infraestrutura, quanto na satisfação do alunado de um modo geral. Dessa forma o presente estudo tem como objetivo analisar a percepção dos alunos do Instituto Federal da Paraíba - IFPB Campus Guarabira, sobre a infraestrutura que o Campus oferece.

\section{EDUCAÇÃO PROFISSIONAL NO BRASIL: OS INSTITUTOS FEDERAIS E O IFPB}

Pelo Decreto $n^{\circ}$ 7.566, de 23 de setembro de 1909, Nilo Peçanha, então Presidente da República, cria a estrutura fundamental da rede de ensino federal da educação profissional no país, com o implemento de 19 Escolas de Aprendizes Artífices, destinadas ao ensino profissional, primário e gratuito.

Segundo Kuenzer (2007), na data de criação desta Lei, o desenvolvimento industrial era praticamente nulo, portanto, a visão de início da educação profissional no Brasil se embasava tão somente na finalidade de educar os órfãos pobres e desvalidos. O ensino técnico, profissional e industrial somente foi abrangido e visto como política de governo, quando foi regulamentado através de uma abordagem específica na Constituição de 1937 (a), quando estabelece no artigo 129 que:

[...] O ensino pré-vocacional e profissional destinado às classes menos favorecidas é, em matéria de educação, o primeiro dever do Estado. Cumpre-lhe dar execução a esse dever, fundando institutos de ensino profissional e subsidiando os de iniciativa dos Estados, dos Municípios e dos indivíduos ou associações particulares e profissionais.

É dever das indústrias e dos sindicatos econômicos criar, na esfera de sua especialidade, escolas de aprendizes, destinadas aos filhos de seus operários ou de seus associados. A lei regulará o cumprimento desse dever e os poderes que caberão ao Estado sobre essas escolas, bem como os auxílios, facilidades e subsídios a lhes serem concedidos pelo poder público. (BRASIL, 1937). 
ISSN 2525-3409 | DOI: http://dx.doi.org/10.33448/rsd-v8i2.561

Entende-se que, no período mencionado, visando diminuir um problema social estrutural, como também, para sanar carência de mão de obra especializada, as classes menos favorecidas passaram a demandar uma maior atenção do estado no que tange a qualificação de mão de obra especializada. Com a emissão da Lei n ${ }^{\circ}$ 378, de 1937 as Escolas de Aprendizes e Artífices foram transformadas em Liceus Profissionais, estipulando assim o ensino profissional em todos os ramos e graus (BRASIL, 1937b).

A partir do ano de 1941, a educação brasileira passou por várias reformulações em suas leis visando novas diretrizes para o ordenamento da educação, ficando estigmatizadas tais mudanças, como a "Reforma Capanema", que estipula pontos fundamentais quando regulamenta que o ensino profissional passa a ser considerado de nível médio, como também, a exigência de exame médico para admissão em escolas industriais (MEC, 2017).

Com tais mudanças, a partir da emissão do Decreto $\mathrm{n}^{\circ} 4.127$, em fevereiro de 1942, o então Presidente da República Getúlio Vargas, define que as escolas de Aprendizes e Artífice são transformadas em Escolas Industriais e Técnicas, na qual os alunos formados em cursos técnicos poderiam ingressar no ensino Superior (BRASIL, 1942c).

Já no governo de Juscelino Kubistchek (1956-1961), a relação do Estado com a economia tem uma significativa atenção e pela primeira vez o setor da educação passa a receber $3,4 \%$ do total de investimentos, visando principalmente a formação de profissionais em detrimento do desenvolvimento do país. Assim, em 1959, as Escolas Industriais e Técnicas são transformadas em autarquias, com o nome de Escolas Técnicas Federais (MEC, 2017).

Com a ascensão do ensino profissional em virtude do processo de industrialização ocorridos nas décadas de 50 e 60, a indústria automobilística surge como impulsionadora da economia brasileira, sendo preciso a formação de novos profissionais para alavancar o desenvolvimento do país, assim, surge as Escolas Técnicas que posteriormente seriam transformadas em Centros Federais de Educação Tecnológica (CEFET), nos termos da Lei n $^{\circ}$ 6.545, de 30 de junho de 1978, no intuito de formar Engenheiros de Operação e Tecnólogos (MEC, 2017).

Os Centros Federais de Educação, de acordo com Cunha (2005), trouxeram um ganho considerável no aumento da produtividade, uma vez que impulsionaram as economias regionais na formação de mão de obra especializada. Dessa forma, Michelotto (2006) afirma que a ampliação e o programa de expansão do ensino trouxeram avanços positivos, em virtude de possibilitar o acesso ao ensino tecnológico e superior a uma parcela maior da população em muitas regiões do país. 
ISSN 2525-3409 | DOI: http://dx.doi.org/10.33448/rsd-v8i2.561

A criação dos Institutos Federais de Educação Ciência e Tecnologia (IFET's) ocorreu através da Lei Federal ${ }^{\circ} 11.892$, de 29 de dezembro de 2008d, que institui no seu artigo $2^{\circ}$, que os Institutos "são instituições de educação superior, básica e profissional, pluricurriculares e multicampi, especializadas na oferta de educação de educação profissional e tecnológica nas diferentes modalidades de ensino". A referida Lei, afirma que cada Instituto Federal será organizado com uma estrutura multicampi e com orçamento anual destinado para cada campus.

No sentido de nortear as ações a serem empreendidas na Educação, a Lei de Diretrizes e Bases da Educação Nacional entende que:

[..] a "educação abrange os processos formativos que se desenvolvem na vida familiar, na convivência humana, no trabalho, nas instituições de ensino e pesquisa, nos movimentos sociais e organizações da sociedade civil e nas manifestações culturais" (LDB, Art. 1, 1996e).

Pacheco (2010, p.7), afirma que "atuar em favor do desenvolvimento local e regional na perspectiva da construção da cidadania constitui uma das finalidades dos Institutos Federais". Ainda de acordo com autor, os Institutos devem ofertar cursos de qualificação, técnicos, superiores de tecnologia, engenharias, formação de professores e programas de pósgraduação lato e stricto sensu comum, a educação especializada e inovadora, tornando-se referência em suas áreas de atuação.

O Plano Nacional de Educação (2014-2024) estipula diretrizes consistentes no tocante ao melhoramento da educação brasileira, como a erradicação do analfabetismo; universalização do atendimento escolar; melhoria na qualidade do ensino, etc., como também, preconiza expandir substancialmente as matrículas na educação profissional de nível médio e sua interiorização visando uma abrangência maior de alunos.

\subsection{A HISTÓRIA DO IFPB E DO CAMPUS GUARABIRA}

O Instituto Federal da Paraíba - IFPB é uma autarquia federal vinculada ao Ministério da Educação e Cultura - MEC. Sendo referência em ensino profissional no estado da Paraíba, o IFPB conta com 21 unidades espalhadas em todo estado, nas cidades de Cabedelo, Cajazeiras, Campina Grande, Catolé do Rocha, Esperança, Guarabira, Itabaiana, Itaporanga, João Pessoa, Monteiro, Patos, Picuí, Princesa Isabel, Santa Rita, Sousa. Conta ainda com Campus Avançado Cabedelo (Centro), Campus Avançado João Pessoa (Mangabeira) e Campus Avançado Soledade (IFPB, 2018). 
O IFPB oferece diversos cursos presenciais e a distância, nas modalidades integrados ao ensino médio, subsequente, superior e pós-graduação. Todos gratuitos.

De acordo com dados do Instituto Federal da Paraíba, o Campus Guarabira foi criado a partir do Plano de Expansão III da Educação Profissional, do Governo Federal. Foi inaugurado no dia 10 de outubro de 2011, na forma de Núcleo Avançado, vindo a se tornar campus no dia 08 de outubro de 2013, com a publicação da Portaria 993 do Ministério da Educação. Em 2017 o Campus conta com um quadro de 72 servidores, sendo 27 Técnicos Administrativos, 45 Docentes efetivos.

Com relação ao pouco tempo de funcionamento, o IFPB campus Guarabira, como também, toda a região do brejo paraibano, já colhem os frutos de sua instalação: são centenas de alunos que estão sendo capacitados, muitos dos quais já começaram a ser inseridos no mercado de trabalho local (IFPB, 2017).

No IFPB Campus Guarabira são oferecidos cursos Técnicos Presenciais de: Contabilidade (108 alunos), Informática (130 alunos), Edificações (126 alunos), todos Integrado ao Ensino Médio, de forma integral, como também, conta com o curso de graduação na modalidade presencial de Tecnologia em Gestão Comercial, no horário noturno (164 alunos) (IFPB, 2018). No ano de 2018, existem o quantitativo regularmente matriculados de 528 alunos, alocados em 08 (oito) salas de aulas, todas equipadas com quadros modernos, televisão, projetor multimídia e acesso a internet, como também wi-fi. Além de 03 laboratórios, Biblioteca, Grêmio Estudantil, Ambulatório Médico, IF News (informativo escolar online), Almoxarifado, Coordenação de Controle Acadêmico. Conforme demonstrado em plantas baixa térreo e superior, através do anexo 01 e planta inferior e superior do bloco administrativo, conforme anexo 2 .

\subsection{INFRAESTRUTURA EDUCACIONAL}

De acordo com a definição do dicionário Houaiss (2011), a palavra infraestrutura significa "suporte, que é a base indispensável à edificação, à manutenção ou ao funcionamento de uma estrutura. Dessa forma fica evidenciado que a infraestrutura é parte importantíssima no processo de ensino-aprendizagem, por ser um dos pilares de sustentação de todo o processo.

Corroborando com o entendimento acima, Grasel (2002), entende que a melhoria do Ensino no Brasil está ligada diretamente ao nível de qualidade das instituições, a partir dos mecanismos que lhe dão suporte, como: instalações, estrutura, serviços acadêmicos, etc. 
Segundo Libâneo (2008), toda a parte de mobília, construções, materiais didáticos devem ser adequados e que seja determinante para promover o trabalho pedagógico, para dessa maneira, favorecer o processo de ensino/aprendizagem.

Francisco (2017), afirma que a infraestrutura consiste em um conjunto de elementos estruturais que impulsiona o desenvolvimento socioeconômico de um determinado local. Torna-se assim fundamental enquanto conjunto estruturante de um determinado local, visando o seu crescimento institucional pleno atendimento da sua missão e visão institucional.

De acordo com Silva (2003, p.113), a “infraestrutura física é um dos eixos fundamentais em torno dos quais se formam as condições de consolidação da qualidade acadêmica das universidades", ilustrando esse entendimento é pertinente afirmar que a infraestrutura é uma parte integrante de suma importância para o pleno desenvolvimento da atividade acadêmica.

Corroborando com o autor Gioielli (2001), entende que até mesmo o formato do campi, já denuncia se o mesmo está preso ao mercado ou se está voltado para a ciência e o desenvolvimento tecnológico.

\section{Metodologia}

A presente pesquisa foi realizada empregando o método de abordagem indutivo, caracteriza-se ainda, quanto a sua finalidade como descritiva e exploratória e quanto a sua abordagem, como quantitativa.

O instrumento utilizado foi uma adaptação do questionário de Pieri e Santos, (2014), que foi alterado para atender as especificidades da realidade presente na infraestrutura existente no setor de educação. O questionário contém 39 perguntas sobre itens relacionados a infraestrutura passíveis de avaliação e está subdividido em 03 partes, sendo: I) identificação, contendo algumas informações dos participantes;II) avaliação quanto a qualidades de itens tecnológicos existentes e, a III) avaliação quanto a qualidade dos serviços existentes.

A população pesquisada corresponde a 528 alunos regularmente matriculados em 2018, estes, que foram abordados através da realização de uma amostragem aleatória simples com uma margem de 95\% de confiança e 5\% de erro, obtendo-se assim, uma amostra de 168 pessoas, englobando todos os cursos oferecidos pelo Campus.

Durante a pesquisa foi observado que alguns alunos ficaram incrédulos a uma mudança no tocante a possível melhora na infraestrutura, em razão da realização da pesquisa, 
fato este que pode ter ocasionado algumas distorções nos dados apresentados. Portanto, seria interessante uma futura abordagem com uma abrangência maior.

Os questionários foram aplicados no Instituto Federal da Paraíba (Campus Guarabira), onde foram percorridas todas as salas de aulas durante o horário diurno e noturno, visando localizar os alunos sorteados com ajuda dos Coordenadores dos Cursos de Contabilidade, Informática e Edificações.

A coleta de dados aconteceu no período de fevereiro a março de 2018. Utilizou-se o Microsoft Office Excel para realizar a tabulação e o tratamento dos dados se deu por meio de Estatística Descritiva.

\section{DISCUSSÃO E RESULTADOS}

A maioria dos alunos está entre 14 e 18 anos, (totalizando 115), correspondente a $68,45 \%$, e o restante tem idade entre 19 e 54 anos (53 alunos) dos questionários respondidos. Quanto ao ingresso dos alunos no Instituto Federal da Paraíba (Campus Guarabira), foi notado que 10,7\% entraram no ano de 2015, 38,1\% em 2016, e 51,2\% em 2017. Esses números refletem uma evasão escolar considerável, que é associada a pobreza de acordo com dados do Formulário de Caracterização Socioeconômica (IFPB, 2017), como também, conforme Nery (2007), o estudante brasileiro precisa ter a idéia claramente deste o princípio dos estudos, da importância e do impacto que a educação promoverá em sua vida, como também, na renda familiar. No tocante ao gênero 54,17\% dos respondentes eram do sexo masculino. Tendo a seguinte distribuição nos cursos: 20,24\% Contabilidade (34 alunos), 30,95\% Gestão Comercial (52 alunos), 26,79\% Informática (45 alunos) e 22,02\% Edificações (37 alunos). O percentual maior no curso de Gestão Comercial deve-se ao total de 52 alunos abrangidos pela pesquisa. A maioria dos participantes é solteiros, $85,71 \%$, uma vez que, a maioria somente está iniciando o ensino médio, seguidos por casados, com $11,31 \%$ e $2,98 \%$ vivem em união estável. No que tange a escolaridade foi observado que $40,48 \%$ dos alunos tem o ensino fundamental, $29,17 \%$ o ensino médio, $7,14 \%$ ensino superior e $23,21 \%$ tem ensino superior incompleto. Foi observado que 78,6\% dos alunos somente estudam e o restante desenvolve outras atividades, além de estudar, como estágio e trabalho.

A Tabela 1 possibilita analisar a qualidade e a existência ou não dos itens de infraestrutura existentes no Instituto Federal da Paraíba (Campus Guarabira), como também, a qualidade dos itens. 
Res., Soc. Dev. 2019; 8(2):e782561

ISSN 2525-3409 | DOI: http://dx.doi.org/10.33448/rsd-v8i2.561

Tabela 1 - Respostas quanto a existência e qualidade dos itens de infraestrutura existentes no Instituto Federal.

\begin{tabular}{|c|c|c|c|c|c|c|}
\hline \multirow{2}{*}{ DESCRIÇÃO } & \multirow{2}{*}{$\begin{array}{l}\text { PERCENTUAL } \\
\text { RESPONDENTE } \\
\text { SIM }\end{array}$} & \multirow{2}{*}{$\begin{array}{c}\text { PERCENTUAL } \\
\text { RESPONDENTE } \\
\text { NÃO }\end{array}$} & \multicolumn{4}{|c|}{ QUALIDADE } \\
\hline & & & FRACO & REGULAR & BOM & ÓTIMO \\
\hline $\begin{array}{l}\text { ÁGUA FILTRADA } \\
\text { /MINERAL }\end{array}$ & $99 \%$ & $1 \%$ & $1 \%$ & $7 \%$ & $46 \%$ & $47 \%$ \\
\hline ÁREA DE VIVÊNCIA & $87 \%$ & $13 \%$ & $22 \%$ & $36 \%$ & $29 \%$ & $13 \%$ \\
\hline AUDITÓRIO & $60 \%$ & $40 \%$ & $9 \%$ & $36 \%$ & $33 \%$ & $23 \%$ \\
\hline BANHEIRO & $100 \%$ & $0 \%$ & $5 \%$ & $18 \%$ & $43 \%$ & $33 \%$ \\
\hline BIBLIOTECA & $99 \%$ & $1 \%$ & $3 \%$ & $20 \%$ & $43 \%$ & $34 \%$ \\
\hline CAMPO DE FUTEBOL & $0 \%$ & $100 \%$ & $0 \%$ & $0 \%$ & $0 \%$ & $0 \%$ \\
\hline CANTINA & $71 \%$ & $29 \%$ & $36 \%$ & $35 \%$ & $24 \%$ & $4 \%$ \\
\hline CARTEIRA & $100 \%$ & $0 \%$ & $2 \%$ & $15 \%$ & $51 \%$ & $32 \%$ \\
\hline CHUVEIRO & $95 \%$ & $5 \%$ & $14 \%$ & $30 \%$ & $35 \%$ & $21 \%$ \\
\hline COZINHA & $22 \%$ & $78 \%$ & $30 \%$ & $46 \%$ & $19 \%$ & $5 \%$ \\
\hline ESTACIONAMENTO & $99 \%$ & $1 \%$ & $8 \%$ & $22 \%$ & $44 \%$ & $26 \%$ \\
\hline ILUMINAÇÃO & $100 \%$ & $0 \%$ & $5 \%$ & $11 \%$ & $41 \%$ & $43 \%$ \\
\hline QUADRA DE ESPORTE & $0 \%$ & $100 \%$ & $0 \%$ & $0 \%$ & $0 \%$ & $0 \%$ \\
\hline QUADRO & $100 \%$ & $0 \%$ & $0 \%$ & $11 \%$ & $46 \%$ & $43 \%$ \\
\hline REFEITÓRIO & $32 \%$ & $68 \%$ & $33 \%$ & $33 \%$ & $28 \%$ & $6 \%$ \\
\hline SALAS DE AULA & $100 \%$ & $0 \%$ & $1 \%$ & $3 \%$ & $48 \%$ & $48 \%$ \\
\hline VIAS DE ACESSO & $92 \%$ & $8 \%$ & $25 \%$ & $28 \%$ & $34 \%$ & $14 \%$ \\
\hline
\end{tabular}

Fonte: Elaboração própria a partir dos dados da pesquisa.

Dentre os itens pesquisados foi evidenciado que sala de aula, carteira, quadro, iluminação e banheiro, se destacaram positivamente, em virtude de corroborarem quanto a sua existência e qualidade, os alunos afirmaram ser bom ou ótimo, com uma média de $43 \%$. Contrastando com os itens mencionados, foi observado que o campus não dispõe de quadra de esporte e campo de futebol, fato este comprometedor, uma vez que o esporte é agente transformador do processo de formação e socialização do aluno, conforme recomenda a Sociedade Brasileira de Medicina no Esporte, que "a implementação da atividade física na infância e na adolescência deve ser considerada como prioridade em nossa sociedade. E acrescenta ainda, que a educação física escolar bem aplicada deve ser considerada essencial e parte indissociável do processo global de educação das crianças e adolescentes". Foi notado também, que a cozinha, refeitório e a cantina, apresentaram grande dissonância ao serem avaliados negativamente com uma média de $36 \%$ entre fraco e regular, principalmente pelo Campus dispor precariamente de apenas uma cantina improvisada para o fornecimento de alimentação.

A Tabela 2 analisa a qualidade e a existência ou não dos itens tecnológicos referentes a infraestrutura no Instituto Federal da Paraíba(Campus Guarabira). 
Res., Soc. Dev. 2019; 8(2):e782561

ISSN 2525-3409 | DOI: http://dx.doi.org/10.33448/rsd-v8i2.561

Tabela 2 - Respostas em percentual quanto qualidade dos itens de tecnológicos existentes.

\begin{tabular}{|c|c|c|c|c|c|c|}
\hline \multirow[b]{2}{*}{ DESCRIÇÃO } & \multirow{2}{*}{$\begin{array}{c}\text { PERCENTUAL } \\
\text { RESPONDENT } \\
\text { E } \\
\text { SIM }\end{array}$} & \multirow{2}{*}{$\begin{array}{c}\text { PERCENTUA } \\
\text { L } \\
\text { RESPONDEN } \\
\text { TE } \\
\text { NÃO } \\
\end{array}$} & \multicolumn{4}{|c|}{ QUALIDADE } \\
\hline & & & $\begin{array}{c}\text { FRAC } \\
\text { O }\end{array}$ & REGULAR & BOM & ÓTIMO \\
\hline AR CONDICIONADO & $97 \%$ & $3 \%$ & $18 \%$ & $17 \%$ & $47 \%$ & $18 \%$ \\
\hline COMPUTADOR & $99 \%$ & $1 \%$ & $4 \%$ & $18 \%$ & $46 \%$ & $33 \%$ \\
\hline COPIADORA & $54 \%$ & $46 \%$ & $24 \%$ & $34 \%$ & $32 \%$ & $9 \%$ \\
\hline DVD & $10 \%$ & $90 \%$ & $19 \%$ & $19 \%$ & $44 \%$ & $19 \%$ \\
\hline IMPRESSORA & $74 \%$ & $26 \%$ & $30 \%$ & $33 \%$ & $29 \%$ & $8 \%$ \\
\hline $\begin{array}{l}\text { LABORATÓRIO DE } \\
\text { CIÊNCIAS }\end{array}$ & $71 \%$ & $29 \%$ & $10 \%$ & $20 \%$ & $48 \%$ & $22 \%$ \\
\hline $\begin{array}{l}\text { LABORATÓRIO DE } \\
\text { INFORMÁTICA }\end{array}$ & $99 \%$ & $1 \%$ & $2 \%$ & $14 \%$ & $47 \%$ & $36 \%$ \\
\hline $\begin{array}{l}\text { LABORATÓRIO } \\
\text { ESPECÍFICO P/ O } \\
\text { CURSO }\end{array}$ & $92 \%$ & $8 \%$ & $10 \%$ & $17 \%$ & $44 \%$ & $29 \%$ \\
\hline PROJETOR & nnot & an & 6 & $1 \mathrm{~nm}$ & exm & nint \\
\hline
\end{tabular}

Fonte: Elaboração própria a partir dos dados da pesquisa.

A maioria dos itens tecnológicos da infraestrutura do campus se mostraram satisfatório, contrastando tão somente, com o item DVD, que em virtude da instituição dispor de equipamentos com novas tecnologias o item pesquisado acabou se mostrando obsoleto. $\mathrm{O}$ item impressora e copiadora foram classificados como insatisfatório, tendo uma avaliação como fraco ou regular correspondente a 30,52\%, demonstrando que o alunado de modo geral encontra-se desprovido do uso desses equipamentos, uma vez que não existe disponível um local para os alunos imprimirem seus trabalhos acadêmicos dentro do campus, contribuindo negativamente para o pleno desenvolvimento das atividades estudantis, e tão pouco, não tem disponibilizado um local que possibilitasse cópias pagas, no entanto, afetaria negativamente, uma vez que a maioria dos alunos é de baixa renda.

A Tabela 3 analisa a qualidade da infraestrutura no tocante a prestação de serviçosdo Campus Guarabira.

Tabela 3 - Respostas quanto qualidade da infraestrutura relativo aos serviços disponibilizados no Campus Guarabira.

\begin{tabular}{|c|c|c|c|c|c|c|}
\hline \multirow[b]{2}{*}{ DESCRIÇÃO } & \multirow{2}{*}{$\begin{array}{c}\text { PERCENTUAL } \\
\text { RESPONDENTE } \\
\text { SIM }\end{array}$} & \multirow{2}{*}{$\begin{array}{c}\text { PERCENT } \\
\text { UAL } \\
\text { RESPOND } \\
\text { ENTE } \\
\text { NÃO } \\
\end{array}$} & \multicolumn{4}{|c|}{ QUALIDADE } \\
\hline & & & FRACO & REGULAR & ВOM & ÓTIMO \\
\hline APOIO PEDAGÓGICO & $98 \%$ & $2 \%$ & $10 \%$ & $19 \%$ & $47 \%$ & $24 \%$ \\
\hline $\begin{array}{l}\text { ATENDIMENTO ESP. AO } \\
\text { ALUNO }\end{array}$ & $90 \%$ & $10 \%$ & $6 \%$ & $20 \%$ & $47 \%$ & $26 \%$ \\
\hline
\end{tabular}


Res., Soc. Dev. 2019; 8(2):e782561

ISSN 2525-3409 | DOI: http://dx.doi.org/10.33448/rsd-v8i2.561

\begin{tabular}{lcccccc} 
COLETA DE LIXO & $99 \%$ & $1 \%$ & $4 \%$ & $15 \%$ & $46 \%$ & $35 \%$ \\
\hline ENERGIA ELÉTRICA & $100 \%$ & $0 \%$ & $2 \%$ & $7 \%$ & $51 \%$ & $39 \%$ \\
\hline ESGOTO & $92 \%$ & $8 \%$ & $9 \%$ & $25 \%$ & $49 \%$ & $17 \%$ \\
\hline INTERNET & $98 \%$ & $2 \%$ & $\mathbf{3 0 \%}$ & $\mathbf{3 2 \%}$ & $29 \%$ & $9 \%$ \\
\hline LIMPEZA & $100 \%$ & $0 \%$ & $2 \%$ & $7 \%$ & $41 \%$ & $49 \%$ \\
\hline MÉDICO & $89 \%$ & $11 \%$ & $11 \%$ & $30 \%$ & $38 \%$ & $21 \%$ \\
\hline SEGURANÇA & $99 \%$ & $1 \%$ & $10 \%$ & $20 \%$ & $49 \%$ & $21 \%$ \\
\hline TRANSPORTE & $95 \%$ & $5 \%$ & $14 \%$ & $33 \%$ & $38 \%$ & $14 \%$ \\
\hline WI-FI & $98 \%$ & $2 \%$ & $\mathbf{5 2 \%}$ & $\mathbf{2 8 \%}$ & $14 \%$ & $6 \%$ \\
\hline
\end{tabular}

Fonte: Elaboração própria a partir dos dados da pesquisa.

Os serviços disponibilizados no campus foram avaliados com uma qualidade que se enquadra como bom ou ótimo, mostrando que os serviços estão acompanhando e colaborando para o desenvolvimento da vida acadêmica no campus, com exceção para o fornecimento internet e a disponibilização de wi-fi, que mostraram grande descontentamento ao serem avaliados negativamente com uma média de 35,55\% classificando com fraco ou regular. Sabe-se que a internet na atualidade é de vital importância para o desenvolvimento de tarefas que são essenciais na vida estudantil, por fornecer praticidade e facilidade no acesso de dados que muitas vezes são disponibilizados pela própria instituição.

Moran (2000) enfatiza que a implantação de tecnologias telemáticas de alta velocidade são essenciais para a disseminação do conhecimento, facilitação e integração entre alunos, professores e a administração.

\section{CONSIDERAÇÕES FINAIS}

O desenvolvimento do artigo possibilitou uma análise sobre a percepção dos alunos sobre a infraestrutura do campus IFPB de Guarabira, analisando a qualidade e existência dos referidos itens. Na maioria dos itens observou-se que estes em geral encontram-se como bom ou ótimo. No entanto, ficou evidenciado que a falta de itens básicos, como campo de futebol e quadra de esporte, prejudica o pleno exercício das atividades esportivas que em muito favorece a atividade dos discentes. A cantina, o refeitório e a cozinha obtiveram avaliações que comprometem a satisfação dos alunos, principalmente em virtude dos últimos itens fornecerem os meios para uma qualidade de vida saudável por serem nestes locais que fornecem o suporte alimentício necessário para o desenvolvimento estudantil, portanto, merecem atenção diferenciada.

Conclui-se, portanto, que a qualidade da infraestrutura disponibilizada no campus está dentro dos padrões de qualidade, contudo, fica demonstrado que é preciso sanar as distorções 
apresentadas com urgência para não prejudicar, sobretudo, a qualidade de vida de seus discentes, vale ressaltar que tais distorções devem-se também ao plano de expansão que cada novo instituto tem, de acordo com o cronograma estipulado pelo Governo Federal, contudo, fica a incógnita quanto ao tempo real para as futuras implantações dos itens que faltam, uma vez que, de acordo com a Emenda Constitucional no. 95 de 15 de dezembro de 2016, que congelou a probabilidade de investimentos, principalmente em infraestrutura por 20 (vinte) exercícios financeiros. Dessa forma, cabe somente a Gestão do Campus se desdobrar para realizar o remanejamento de financeiro de verbas, visando pequenas melhorias estruturais.

\section{Referências}

BRASIL. Constituição da República Federativa do Brasil. Rio de Janeiro, RJ. Senado Federal: Centro Gráfico, 1937a.

BRASIL, 1937. Lei no 378 de 13 de janeiro de 1937. Dá nova organização ao Ministério da educação e Saúde Pública. Diário Oficial. Rio de Janeiro. 15 de jun. 1937b.

BRASIL. Decreto 4.127 de 25 de fevereiro de 1942. Estabelece as bases de organização da rede federal de estabelecimentos de ensino industrial. Rio de Janeiro. 27 fev. 1942c.

BRASIL, 2008. Lei $\mathrm{n}^{\mathbf{0}} 11.892$, de 29 de dezembro de 2008. Institui a Rede Federal de Educação Profissional, Científica e Tecnológica, cria os Institutos Federais de Educação, Ciência e Tecnologia, e dá outras providências. Brasília. DF. 29 dez. 2008d.

BRASIL. Lei de Diretrizes e Bases da Educação Nacional. Lei no 9.394, 20 de dezembro de 1996. Estabelece as diretrizes e bases da educação nacional. Brasília. DF. 20 dez. 1996e.

BRASIL. Expansão da Rede Federal de Educação Profissional, Científica e Tecnológica. 2017. Disponível em: <http://redefederal.mec.gov.br/>. Acesso em 02/10/2017.

BRASIL. Emenda Constitucional $n^{\circ}$ 95, DE 15 DE DEZEMBRO DE 2016. Altera o Ato das Disposições Constitucionais Transitórias, para instituir o Novo Regime Fiscal, e dá outras providências. $\quad$ Disponível em <http://www.planalto.gov.br/ccivil_03/constituicao/emendas/emc/emc95.htm> . Acesso em $14 / 06 / 2018$.

CARDOSO, André Luis Rabelo. A qualidade do gasto público: o caso dos Institutos Federais de Educação. 2016. [100] f., il. Dissertação (Mestrado Profissionalizante em Gestão Pública) - Universidade de Brasília, Brasília, 2016.

COMENTTO PESQUISA DE OPINIÃO. Calculadora amostral. Disponível em http://comentto.com/blog/calculadora-amostral/. Acesso em 10/01/2018.

DICIONÁRIO HOUAISS Conciso / Instituto Antonio. HOUAISS, organizador; editor responsável Mauro de Salles Villar. São Paulo: Moderna, 2011. 
FRANCISCO, Wagner de Cerqueira e. "Infraestrutura"; Brasil Escola. Disponível em <http://brasilescola.uol.com.br/geografia/infraestrutura.htm>. Acesso em 19 de setembro de 2017.

GIOIELLI, Rafael. Forma e Conteúdo: O mau uso do espaço contraria a razão de ser das universidades. Caros Amigos, Ed. Especial, São Paulo, n. 9, p.26. Nov/2001.

GRASEL, DIRCEU. Avaliação de Qualidade e Melhoria do Ensino nas Instituições Federais de Ensino Superior Brasileiras. Revista de estudos sociais. 2002. V. 4 No 7.

Instituto Federal da Paraíba. Portal do Estudante. Ministério da Educação. Disponívelem: $<$ https://estudante.ifpb.edu.br/cursos/?cidade $=24 \&$ modalidade $=\&$ nome $=\&$ form acao $=\&$ nivel_formacao $=$ TECNICO\&turno $=\&$ forma_acesso $=>$.

Acesso em 11/12/2017.

Instituto Federal da Paraíba. Sobre o IFPB. Disponível em: <http://www.ifpb.edu.br/institucional/sobre-o-ifpb> Acesso em 20/03/2018.

KUENZER, A. Z. Ensino médio: construindo uma proposta para os que vivem do trabalho. São Paulo: Cortez, 2007.

LIBÂNEO, J.; FERREIRA, J.; SEABRA, M. Educação escolar: políticas, estrutura e organização. 6 ed. São Paulo: Cortez, 2008.

MARQUES, Carolina Sampaio.Pereira, BRENO Augusto Diniz. Alves, JULIANO alves. A Infraestrutura Universitária: Uma Análise Em Uma IES Pública. 2010.

MICHELOTTO, R. M.; COELHO, R. H.; ZAINKO, M. A. S.A política de expansão da educação superior e a proposta de reforma universitária do governo Lula. Educar, Curitiba, 2006. Editora UFPRE.

Ministério da Educação - MEC 2012. Relatório da Comissão Constituída pela Portaria no 126/2012, sobre a Análise sobre a Expansão das Universidades Federais 2003 a 2012. Disponível em <http://www.andifes.org.br/wp-content/files_flutter/1361475592UFMT__Maria_Lucia_Neder_-_Relatorio_REUNI.pdf> Acesso em 05/10/2017.

Ministério da Educação. MEC 2017. Centenário da Rede Federal de Educação Profissional e Tecnológica. Disponível em: <http://portal.mec.gov.br/setec/arquivos/centenario/historico_educacao_profissional.pdf >. Acesso em 28/12/2017.

MORAN, José Manuel. Ensino e Aprendizagem Inovadores com Tecnologias. Informática na Educação: Teoria e Prática. PGIE-UFRGS. Vol. 3, n 01, Setembro, 2000.

NERY, Marcelo. Motivos da Evasão Escolar. 2007. Disponível em < http://www.bibliotecadigital.abong.org.br/bitstream/handle/11465/1166/1789.pdf?sequence=1 $>$ Acesso em 12/06/2018. 
NEVES, C. E. B. A estrutura e o funcionamento do ensino superior no Brasil. In:SOARES, Maria Suzana Arrosa (Org.). A educação superior no Brasil. Porto Alegre: UESCO/IESALC, 2002.

PACHECO, Eliezer Moreira. Os Institutos Federais: Uma Revolução na Educação Profissional e Tecnológica, Natal: IFRN, 2010.

PEREIRA, Francisco. Possibilidades da Construção de uma Educação Emancipadora em Cursos Tecnológicos: uma abordagem a partir de dois cursos localizados em Goiânia e Anápolis. Goiânia-GO, 2008.

Portal da Rede Federal de Educação Profissional Científica e Tecnológica. Centenário da Rede Federal de Educação Profissional e Tecnológica. Disponível em: $<$ Http://portal.mec.gov.br/setec/arquivos/centenario/historico_ centenario-da-rede-federal-deeducacao-profissional-e-tecnologica>. Acesso em 06/01/2018.

Portal da Rede Federal de Educação Profissional Científica e Tecnológica. Centenário da Rede Federal de Educação Profissional e Tecnológica.

Revista Brasileira de Medicina no Esporte. Atividade física e saúde na infância e adolescência. Disponível em <http://www.scielo.br/scielo.php?pid=S151786921998000400002\&script=sci_arttext\&tlng=pt> Acesso em 13/06/2018.

SANTOS, Alexandre André dos.PIERI, Renan Gomes de. Uma Proposta para o Índice de Infraestrutura Escolar e o Índice de Formação de Professores.

Brasília-DF, INEP/MEC, 2014. Disponível em:

<http://portal.inep.gov.br/documents/186968/485287/Uma+Proposta+para+o+\%C3\%8Dndice + de+Infraestrutura+Escolar+e+o+\%C3\%8Dndice+de+Forma\%C3\%A7\%C3\%A3o+de+Profe ssores/19746685-13b1-4daf-88cb-08871cd79b42?version=1.0> Acesso em 10/09/2017.

SANTOS, Fabrício do Nascimento. ARAÚJO, Richard Medeiros de. COSTA, Fernando Torres da. JUNIOR, Thiago Ferreira Dias. Avaliando o PRONATEC no IFPB: um Estudo sobre Implementação. Revista UNIABEU. Belford Roxo V.9 Número 21 JANEIRO-ABRIL de 2016.

SILVA, Eliane Garcia da. A gestão da infra-estrutura física das Universidades no contexto do planejamento estratégico: estudo de caso em uma instituição universitária goiana. Florianópolis, UFSC, Programa de pós-graduação em Engenharia de Produção, 2003.

UNISESCAP. Noções de Tecnologia da Informação. 2017. Disponível em: $<$ https://slidex.tips/download/nooes-de-tecnologia-da-informaao>. Acesso em 22/03/2018. 